Polymer Journal, Vol. 2, No. 2, pp 192-198 (1971)

\title{
Photopolymerization of Methyl Methacrylate Initiated by Iodine-Triethylamine System
}

\author{
Naokazu SAKota and Toyohiko NAgASAKI \\ Department of Industrial Chemistry, \\ Faculty of Engineering, Ehime University, \\ Bunkyo-cho, Matsuyama, Japan. \\ Sumihiro SAKAI \\ Kanae Paint Co. Ltd., Joto-ku, Osaka, Japan.
}

(Received October 12, 1970)

\begin{abstract}
The photopolymerization of methyl methacrylate in the presence of iodine and triethylamine was investigated to clarify the initiation mechanism in this system. The polymerization proceeded according to a radical mechanism. It was confirmed that triethylamine hydroiodide formed during the polymerization process did not act as a photosensitizer by itself. On the other hand the red-brown oily material, which was obtained from the mother liquor of the crystalline triethylamine hydroiodide, initiated the photopolymerization of methyl methacrylate in the presence of triethylamine or sodium thiosulfate without an induction period. The results of elementary analysis, measurements of infrared spectra, and thin-layer chromatography, suggest that the oily material contained, inter alia, $N, N$-diethyl- $\alpha$-iodoethylamine.

A graft polymer was obtained in the photopolymerization of methyl methacrylate in the presence of iodine and poly $(N, N$-diethylallylamine). This fact also would suggest that with irradiation by ultraviolet light the iodine-triethylamine charge-transfer complex was converted into $N, N$-diethyl- $\alpha$-iodoethylamine, the photolysis of which provided the primary radicals to initiate the polymerization of methyl methacrylate.

KEY WORDS Photopolymerization / Methyl Methacrylate / Iodine / Triethylamine / Radical / Triethylamine Hydroiodide / Charge-Transfer Complex / Sodium Thiosulfate / Graft Polymer / Poly $(N, N$-diethylallylamine) /
\end{abstract}

It is well known that iodine can act as an electron acceptor to form charge-transfer complexes with electron donors such as amines, ${ }^{1-3}$ amides, ${ }^{4}$ ethers, ${ }^{5}$ alcohols, ${ }^{5}$ aromatic hydrocarbons, ${ }^{6}$ and some of the olefins. ${ }^{7}$ On the iodinetriethylamine charge-transfer complex in particular, a number of studies have been reported. ${ }^{8-12}$ The cationic polymerization of alkyl vinyl ethers, ${ }^{13}$ styrene, ${ }^{14}$ substituted styrenes, ${ }^{15}$ and $N$-vinylcarbazole ${ }^{16}$ with iodine have already been investigated, and in these cases it was proposed that charge-transfer complexes of iodine and vinyl monomers participated directly in the initiation of the polymerization. Tsuji, et al. ${ }^{17}$ however, have detected free radicals in the polymerization system of iodine and alkyl vinyl ether by ESR, and have suggested the possibility of a radical polymerization by iodine in the presence of an appropriate vinyl monomer. Although Pramanick and his coworker ${ }^{18}$ described how the radical polymerization of methyl methacrylate could be thermally initiated in the presence of iodine and some types of amines, no detailed initiation mechanism has yet been put forward. In this study the initiation mechanism in the photopolymerization of methyl methacrylate in the presence of iodine and triethylamine is discussed.

\section{EXPERIMENTAL}

\section{Materials \\ Methyl methacrylate(MMA) was washed with a saturated aqueous solution of sodium bisulfite,}




\section{Photopolymerization of Methyl Methacrylate}

an aqueous solution containing $20-\%$ sodium chloride and 5-\% sodium hydroxide, and a 20-\% aqueous solution of sodium chloride, successively. It was dried over anhydrous sodium sulfate and then distilled in a nitrogen stream under reduced pressure. Iodine was purified by sublimation several times in the presence of potassium iodide and calcium oxide. Triethylamine(TEA) was dried over potassium hydroxide and calcium hydride, and then distilled. The fraction distilled at $89.2-90.0^{\circ} \mathrm{C}$ was used for the experiments. The other amines were also purified by drying over potassium hydroxide and by fractional distillation. $\operatorname{Poly}(N, N$-diethylallylamine) (PDEAA) was prepared by reduction of $\operatorname{poly}(N, N$-diethylacrylamide) according to the method of Cohen, et al. ${ }^{19}$ It showed no absorption band of the carbonyl group in the infrared spectrum, and its intrinsic viscosity was 0.336 in tetrahydrofuran solution at $30^{\circ} \mathrm{C}$.

\section{Procedure}

Defined amounts of MMA, $\mathrm{I}_{2}$, and amine for polymerization were placed in a glass tube which was then degassed by the freeze-thaw method. The photopolymerization was carried out by irradiating the sealed tubes with ultraviolet light from a $300 \mathrm{~W}$ high-pressure mercury lamp (PIH 300 made by Eiko). The sealed tubes were placed on a rotating drum around the lamp in an air bath at $35^{\circ} \mathrm{C}$. A low-pressure luminescent discharge tube (FL-20 BL made by Toshiba) was also used for the preliminary experiments detailed in Table $\mathrm{I}$. The reaction mixture obtained by photopolymerization was poured into an excess of methanol. The polymer was filtered off and dried in vacuo at $60^{\circ} \mathrm{C}$ for $24 \mathrm{hr}$. The polymerization rates were determined from the amounts of polymer at each reaction time. The separation of graft polymer from the reaction product in the $I_{2}$-PDEAA system was achieved by extraction with acetonitrile in a Soxhlet extractor for $20 \mathrm{hr}$.

The electronic spectrum of the $\mathrm{I}_{2}$-TEA complex was determined with a 2-mm cell in MMA solution using a Jasco Model ORD/UV 5 Spectropolarimeter.

\section{RESULTS AND DISCUSSION}

The results of the photosensitized polymeri-
Table I. Polymerization of MMA by various donors (D) and $\mathbf{I}_{2}$ systems

\begin{tabular}{lccc}
\hline & \multicolumn{2}{c}{ conversion, \%c } \\
\cline { 2 - 3 } \multicolumn{1}{c}{ Donor } & $\begin{array}{c}\text { Photopolymeri- } \\
\text { zation }\end{array}$ & $\begin{array}{c}\text { Thermal } \\
\text { polymeri- } \\
\text { zation } \\
\mathbf{I}_{2}+\mathrm{D}\end{array}$ \\
\cline { 2 - 4 } $\mathrm{I}_{2}+\mathrm{D}$ & $\mathrm{D}$ & - \\
\hline Ammonia $^{\mathrm{a}}$ & 0 & - & 0 \\
Ethylamine $^{\mathrm{y}}$ & 0 & 2.6 & 0 \\
Diethylamine & 5.6 & 4.3 & 0 \\
Triethylamine & 13.4 & 3.8 & 0.1 \\
Cyclohexylamine & 9.9 & 2.7 & 0.3 \\
Piperidine & 10.3 & 3.6 & 0.3 \\
Ethylenediamine & 18.4 & 1.2 & 2.3 \\
Hexamethylenediamine & 19.6 & 3.1 & 0 \\
Diethylenetriamine & 15.8 & 3.5 & 6.4 \\
Triethylenetetramine & 14.1 & 3.7 & 14.3 \\
Pyridine & 0 & 1.9 & 0 \\
Aniline & 0 & - & - \\
Dimethylaniline & 0 & - & - \\
Ethanolamine & 21.0 & 1.5 & 0.5 \\
Triethanolamine & 33.4 & 3.3 & 1.7 \\
Dimethylacetamide & 0 & - & - \\
Ethyl Alcohol & 0 & - & - \\
Ethyl Ether & 0 & - & - \\
\hline a & 0.3 & &
\end{tabular}

a 25-\% Aqueous solution.

b $60-\%$ Aqueous solution.

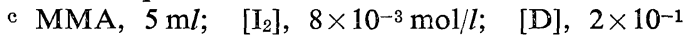
$\mathrm{mol} / l$. Photopolymerizations were carried out for $5 \mathrm{hr}$ at $30^{\circ} \mathrm{C}$, and thermal polymerizations for 5 hr at $33^{\circ} \mathrm{C}$.

zation of MMA in the presence of $\mathrm{I}_{2}$ and various amines are shown in Table $I . I_{2}$ seems to act as a photosensitizer in the presence of aliphatic di- and tri-alkyl amines, and the accelerating effect of tertiary amines are distinguishable from those of primary and secondary amines for the polymerization of MMA. In other experiments the photosensitizing effect of the iodine-triethylamine system has also been confirmed for the polymerization of acrylonitrile, styrene, and ethyl acrylate.

Although $\mathrm{I}_{2}$, known as a powerful radical scavenger, inhibited the photopolymerization of MMA by itself, it was able to initiate the photopolymerization of MMA in the presence of TEA with an induction period (Figure 1). In the presence of only TEA, however, a rate of polymerization slightly higher than that of MMA alone was obtained. This 


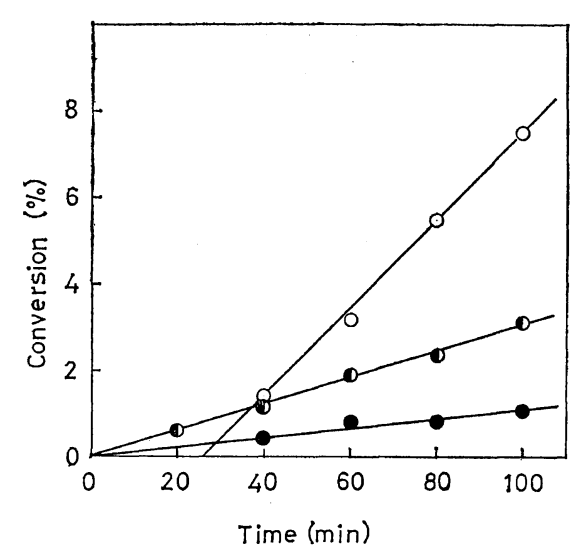

Figure 1. Photopolymerization of MMA by $\mathrm{I}_{2}$ TEA system at $35^{\circ} \mathrm{C}$ : - - MMA, $5 \mathrm{ml}$; MMA, $5 \mathrm{ml}$, [TEA], $4 \times 10^{-1} \mathrm{~mol} / l$, - - , MMA, $5 \mathrm{ml}$; [TEA], $4 \times 10^{-1} \mathrm{~mol} / l,\left[\mathrm{I}_{2}\right], 8 \times 10^{-3} \mathrm{~mol} / l$.

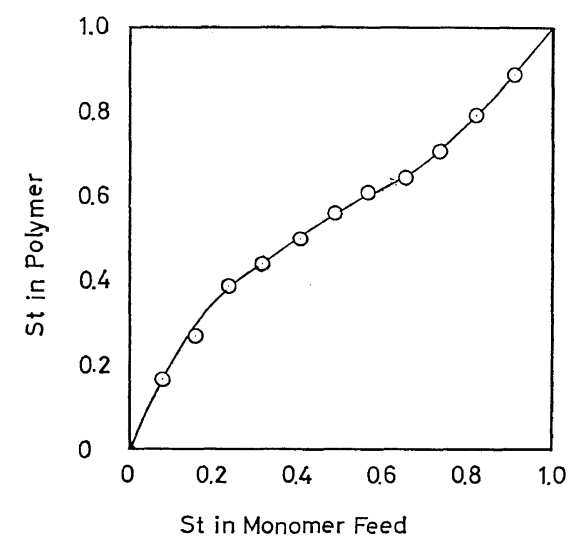

Figure 2. Copolymerization of MMA with styrene at $35^{\circ} \mathrm{C}$ : $\mathrm{MMA}+\mathrm{St}, 6 \mathrm{ml}$; [TEA], $2 \times 10^{-1} \mathrm{~mol} / l$; $\left[\mathrm{I}_{2}\right], 4 \times 10^{-3} \mathrm{~mol} / \mathrm{l}$.

fact would be explained by the relatively large photolysability of the $\mathrm{H}-\mathrm{C}_{\alpha}$ linkage of TEA, and by the participation of the TEA radicals in the photopolymerization of MMA. Moreover, polymerization by this system was inhibited with oxygen and was also retarded by hydroquinone, but was accelerated with water. As shown in Figure 2, the photosensitized copolymerization of MMA and styrene by the $I_{2}$-TEA system indicates a characteristic composition curve of radical polymerization. The overall rate of photopolymerization of MMA $\left(R_{p}\right)$, when the molar ratio of $I_{2}$ to TEA was kept constant at $1 / 50$ and the concentration of $I_{2}$ was varied

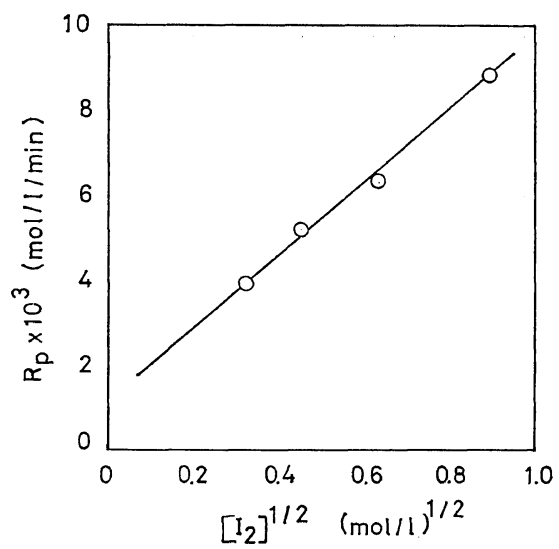

Figure 3. Effect of iodine concentration on the rate of photopolymerizatixn of $\mathrm{MMA}$ at $35^{\circ} \mathrm{C}$ : MMA, $5 \mathrm{ml} ;\left[\mathrm{I}_{2}\right] /[\mathrm{TEA}], 1 / 50$.

from 0.001 to $0.008 \mathrm{~mol} / l$, was measured and plotted against the square root of the $I_{2}$ concentration in Figure 3. As already mentioned, MMA can photopolymerize in the presence of TEA a little faster than without TEA and, therefore, the $R_{p}$ s should not be strictly zero without $\mathbf{I}_{2}$. However, in relatively higher concentrations of $I_{2}$, the photopolymerization by TEA could be ignored. Hence, the result in Figure 3 indicates that at higher $I_{2}$ concentrations the polymerization rate is proportional to the square root of the concentration of the $I_{2}-$ TEA charge-transfer complex. The molecular weights ${ }^{27}$ (in benzene at $30^{\circ} \mathrm{C}$ ) of poly-MMA obtained at $\left[\mathrm{I}_{2}\right]=8 \times 10^{-3}, 4 \times 10^{-3}$, and $2 \times 10^{-3}\left(\left[\mathrm{I}_{2}\right] /[\mathrm{TEA}]=\right.$ $1 / 50$ ) were 160000,185000 , and 228000 , respectively. These facts indicate that the photo-

Table II. Effect of solvent on the photopolymerization of $\mathrm{MMA}$ at $30^{\circ} \mathrm{C}^{\mathrm{a}}$

\begin{tabular}{lccr}
\hline \multicolumn{1}{c}{ Solvent } & $\begin{array}{c}\text { Induction } \\
\text { period, min }\end{array}$ & $\begin{array}{c}\boldsymbol{R}_{p}, \\
\% / \mathrm{hr}\end{array}$ & $\varepsilon^{\mathrm{b}}$ \\
\hline Acetone & 0 & 8.7 & 20.7 \\
1,2-Dichloroethane & 0 & 7.3 & \\
Acetonitrile & 0 & 6.5 & 37.5 \\
Methyl Alcohol & 0 & 6.3 & 32.6 \\
Benzene & 36 & 4.3 & 2.3 \\
Ethyl Acetate & 37 & 3.5 & \\
None & 28 & 5.6 & \\
\hline
\end{tabular}

a MMA, $4 \mathrm{~m} l$; Solvent, $3 \mathrm{~m} l ;\left[\mathrm{I}_{2}\right], 4 \times 10^{-3} \mathrm{~mol} / l$; [TEA], $2 \times 10^{-1} \mathrm{~mol} / l$.

b Dielectric constant. 
polymerization of MMA in this system proceeds according to a radical mechanism accompanied by bimolecular termination.

The solvent effect on the photopolymerization of MMA by the $I_{2}$-TEA system is shown in Table II, which indicates that no induction period is observed in the use of solvents with high dielectric constant.

The conversion vs. time curves of the polymerization are shown in Figure 4, in which the concentrations of TEA are varied within the range of 0.04 and $0.8 \mathrm{~mol} / l$ at a constant concentration of $\mathrm{I}_{2}\left(8 \times 10^{-3} \mathrm{~mol} / \mathrm{l}\right)$. It is obvious that the $R_{p}$ increases and the induction period becomes shorter with the increase of TEA concentration. Nagakura ${ }^{8}$ has reported that the equilibrium constants of the $\mathrm{I}_{2}$-TEA chargetransfer complex in $n$-heptane were 3310 at $30^{\circ} \mathrm{C}$ and 1740 at $40^{\circ} \mathrm{C}$. In Figure 5, the equilibrium constants of the $I_{2}$-TEA complex in MMA were assumed to be 1000,2500 , and 4000 at $35^{\circ} \mathrm{C}$, and the concentration of free iodine estimated from this assumption were plotted against induction periods obtained from Figure 4. It was found that even in the absence of the free iodine molecule the induction period still remained. This suggests that primary radicals for the initiation could not be produced directly by the

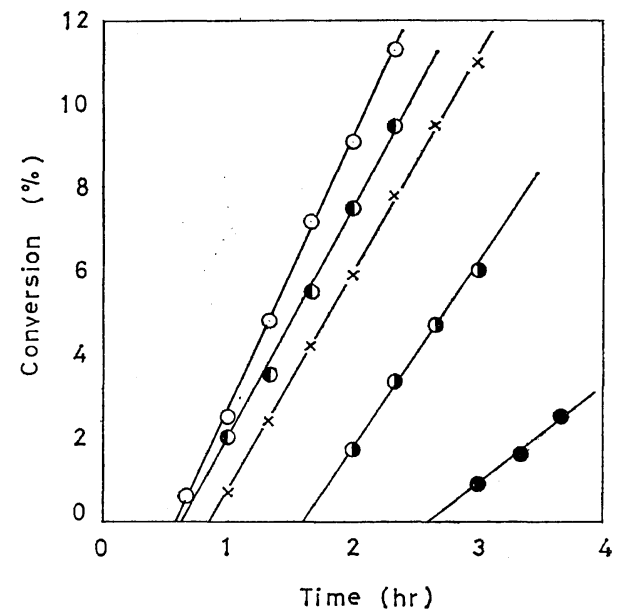

Figure 4. Effect of TEA concentration on the rate of photopolymerization of MMA at $35^{\circ} \mathrm{C}:\left[\mathrm{I}_{2}\right]$, $8 \times 10^{-3} \mathrm{~mol} / l ;$; - , [TEA], $8 \times 10^{-1} \mathrm{~mol} / l ;-O-$, [TEA], $4 \times 10^{-1} \mathrm{~mol} / l ;-\times-$, [TEA], $2 \times 10^{-1} \mathrm{~mol} / l$; - - , [TEA], $8 \times 10^{-2} \mathrm{~mol} / l ;-\longrightarrow$, [TEA], $4 \times 10^{-2}$ $\mathrm{mol} / l$.

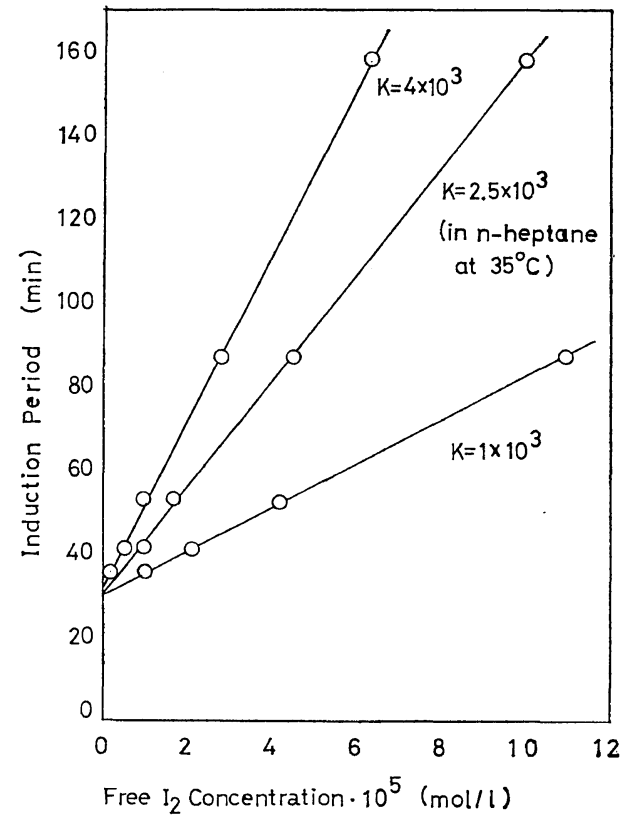

Figure 5. Dependence of induction period on free iodine concentration.

photolysis of the $\mathrm{I}_{2}$-TEA charge-transfer complex but from the intermediate compounds derived from the complex by irradiation.

In the course of the photopolymerization with the $\mathrm{I}_{2}$-TEA system a crystalline material appeared at higher concentrations of $I_{2}$ and was identified as triethylamine hydroiodide by elementary analysis; measurement of melting point and by infrared spectrum. Boule, ${ }^{9}$ and Bist and Person ${ }^{10}$ pointed out that triethylamine hydroiodide(TEA-HI) was formed by thermal decomposition of the $\mathrm{I}_{2}-$ TEA charge-transfer complex in dioxane. Schmulbach, et al., ${ }^{11}$ have also suggested that the formation of triethylamine hydroiodide could take place by hydrolysis of the $\mathrm{I}_{2}$-TEA complex in $n$-heptane. In our investigation, however, we confirmed that triethylamine hydroiodide was formed even in the completely moisture-free MMA solution, by adding $I_{2}$ with an excess amount of TEA and allowing it overnight in the dark at room temperature. Polymerization was found not to have occured by that time when crystalline TEAHI precipitated out. Therefore, it is reasonable to believe that triethylamine hydroiodide was produced not by hydrolysis with moisture but 


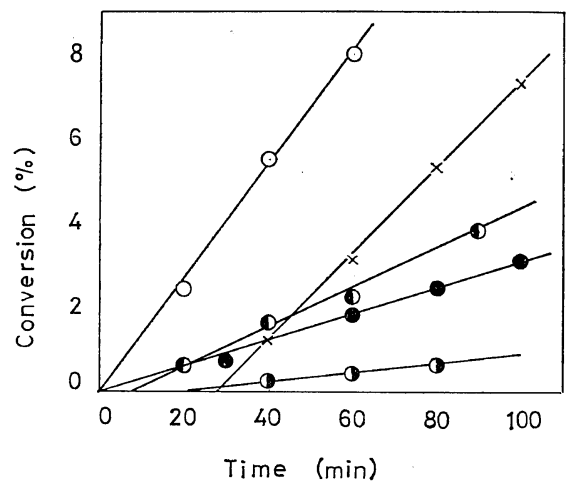

Figure 6. Effect of TEA-HI and oily product on photopolymerization of $\mathrm{MMA}$ at $35^{\circ} \mathrm{C}$ : MMA, $5 \mathrm{ml}$, TEA-HI, $10 \mathrm{mg}$; - - MMA, $5 \mathrm{ml}$, TEA, $0.3 \mathrm{~m} l$; - - MMA, $5 \mathrm{~m} l$, TEA, $0.3 \mathrm{~m} l$, TEA-HI, $10 \mathrm{mg}$; - $\times$, MMA, $5 \mathrm{ml}$, TEA, $0.3 \mathrm{ml}$, $\mathrm{I}_{2}, 10 \mathrm{mg}$; - $\mathrm{O}-$, MMA, $5 \mathrm{ml}$, TEA, $0.3 \mathrm{ml}$, oily product, $10 \mathrm{mg}$.

by the abstraction of an hydrogen atom from the TEA molecule. Since the photopolymerization rate of MMA by the $\mathrm{I}_{2}$-TEA system is larger than that of the TEA-HI system in Figure 6, triethylamine hydroiodide seems not to play a direct role in the initiation reaction.

On the other hand, the red-brown oily product which was obtained by vacuum concentration of the mother liquid of crystalline TEA-HI was able to initiate the photopolymerization of MMA in the presence of TEA without any induction period, as shown in Figure 6. The infrared spectrum of the oily product showed no absorption band for the carbonyl group and differed from that of ethyl $\alpha$-iodomethyl acrylate. The elementary analysis of the oily product, which was purified by means of extraction with chloroform and then washed with aqueous solution of sodium thiosulfate, gave results of $\mathrm{C}, 52.87 \%$; $\mathrm{H}, 6.95 \% ; \mathrm{N}, 7.68 \%$. The oily material was also found to contain $34.23 \%$ of total iodine and $25.63 \%$ of ionic iodine. The results of thinlayer chromatography suggested that more than three compounds were contained in the oily product. These facts suggest that the oily product might be a mixture of $N, N$-diethyl- $\alpha$ iodoethylamine, $\alpha-N, N$-diethylaminoethyltriethyl ammonium iodide, $N, N$-diethylvinylamine and so on which could be derived from the abstraction of hydrogen atoms from TEA. According to Lahan, et al.,$^{20}$ however, $\mathrm{N}, \mathrm{N}$-diethylvinylamine was unstable and gave a polymer very easily-hence the presence of the compound in the oily product is doubtful.

In this work, triethylamine hydroiodide was also obtained from the tetrahydrofuran solution of iodine and an excess of triethylamine, as well as MMA solution. After filtration of the crystalline TEA-HI, the tetrahydrofuran solution was subjected to vacuum concentration. The residual material gave an infrared absorption spectrum similar to that of the oily material obtained from the MMA solution, and also indicated it had a photosensitizing effect on the polymerization of MMA. The rate of polymerization by this material was equal to that of the oily material obtained from $I_{2}$-TEA in MMA.

The photopolymerization of MMA was carried out in the presence of $\mathrm{I}_{2}$ and $\operatorname{poly}(N, N$-diethylallylamine) (PDEAA) which has a similar chemical structure to that of TEA. Table III shows that the $\mathrm{I}_{2}-\mathrm{PDEAA}$ system has the same sensitizing action as $\mathbf{I}_{2}-$ TEA. The high graft ratio in this system showed larger graft efficiency than that of PDEAA-2,2-azobisisobutyronitrile (AIBN). These facts suggest that the photopolymerization of MMA with $\mathrm{I}_{2}$ - PDEAA is initiated by the same mechanism as with $\mathbb{I}_{2}$-TEA, and that the graft polymer does not appear to have resulted from the chain transfer reaction

Table III. Photopolymerization of MMA by PDEAA- $\mathrm{I}_{2}$ system

\begin{tabular}{lcccc}
\hline \multicolumn{1}{c}{ System } & Conversion, $\%$ & Graft polymer, g & Graft ratio, $\%$ & Graft efficiency, $\%$ \\
\hline PDEAA-I $^{\mathrm{a}}$ & 11.6 & 0.3074 & 514.8 & 47.2 \\
PDEAA $^{\mathrm{b}}$ & 3.4 & 0.1168 & 133.6 & 41.7 \\
PDEAA-AIBN $^{\mathrm{c}}$ & 10.5 & 0.0580 & 16.0 & 1.6 \\
\hline
\end{tabular}

a MMA, $5 \mathrm{ml}$; PDEAA, $50 \mathrm{mg} ; \mathrm{I}_{2}, 10 \mathrm{mg} ; 3 \mathrm{hr}$ at $35^{\circ} \mathrm{C}$.

b MMA, $5 \mathrm{ml}$; PDEAA, $50 \mathrm{mg} ; 3 \mathrm{hr}$ at $35^{\circ} \mathrm{C}$.

c MMA, $5 \mathrm{ml}$; PDEAA, $50 \mathrm{mg}$; AIBN, $8 \mathrm{mg} ; 40 \mathrm{~min}$ at $35^{\circ} \mathrm{C}$. 


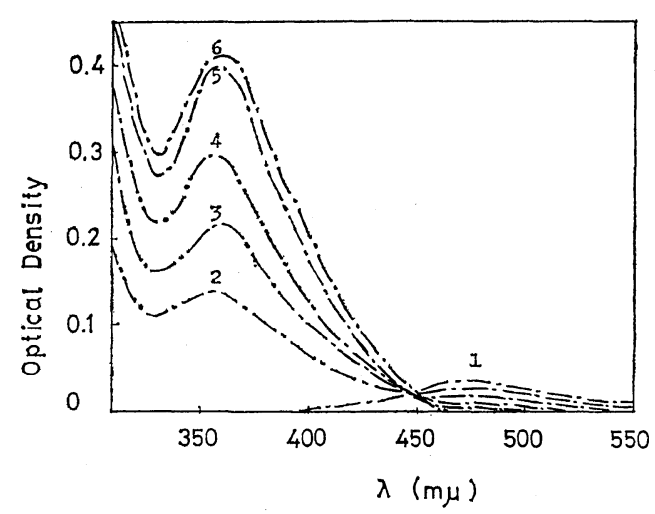

Figure 7. Electronic spectra of $\mathrm{I}_{2}$-TEA system in MMA: $1,\left[\mathrm{I}_{2}\right], 2 \times 10^{-4} \mathrm{~mol} / l ; 2,\left[\mathrm{I}_{2}\right], 2 \times 10^{-4} \mathrm{~mol} / l$, [TEA], $4 \times 10^{-5} \mathrm{~mol} / l ; 3,\left[\mathrm{I}_{2}\right], 2 \times 10^{-4} \mathrm{~mol} / l$, [TEA], $8 \times 10^{-5} \mathrm{~mol} / l ; 4,\left[\mathrm{I}_{2}\right], 2 \times 10^{-4} \mathrm{~mol} / l$, [TEA], $1.2 \times$ $10^{-4} \mathrm{~mol} / l ; 5,\left[\mathrm{I}_{2}\right], 2 \times 10^{-4} \mathrm{~mol} / l, \quad[\mathrm{TEA}], 2 \times 10^{-4}$ $\mathrm{mol} / l ; 6,\left[\mathrm{I}_{2}\right], 2 \times 10^{-4} \mathrm{~mol} / l,[\mathrm{TEA}], 8 \times 10^{-4} \mathrm{~mol} / l$.

of PDEAA with growing poly-MMA radicals.

In this study, iodine in MMA was found to have an absorption maximum at $475 \mathrm{~m} \mu$. In the presence of air, the absorbance at $475 \mathrm{~m} \mu$ decreased with the irradiation time of UV light, and in vacuo, the decrease in irradiation was accompanied by the appearance of a new band at $360 \mathrm{~m} \mu$. Adding TEA to the solution of $\mathrm{I}_{2}$ in MMA, the absorbance of the 475-m $\mu$ band decreased with increasing concentrations of TEA, and then a new band appeared at $360 \mathrm{~m} \mu$. The electronic spectra of $\mathrm{I}_{2}$ and TEA in MMA are shown in Figure 7. The molar extinction coefficient of the $360 \mathrm{~m} \mu$ absorption band of $\mathrm{I}_{2}$ TEA in MMA $\left(\varepsilon_{360}=1.13 \times 10^{4}\right)$ is about three times as large as that observed in $n$-heptane. ${ }^{8}$ Thus, the $360-\mathrm{m} \mu$ absorption band of $\mathrm{I}_{2}-\mathrm{TEA}$ in MMA, which appeared on irradiation, apparently cannot be ascribed only to the complexed iodine molecule. According to the results obtained by Buckles, et al., the $\mathrm{I}_{3}{ }^{-}$ion has two absorption maxima in ethylene chloride $\left(\varepsilon_{295}=\right.$ $4.51 \times 10^{4}$ and $\left.\varepsilon_{365}=2.53 \times 10^{4}\right){ }^{21} \quad$ Toyoda and Person $^{12}$ have also reported that the absorption bands of the $\mathrm{I}_{3}^{-}$ion appeared at $363 \mathrm{~m} \mu$ and $295 \mathrm{~m} \mu$ in a dioxane solution of $\mathrm{I}_{2}$-TEA. Consequently, the $360-\mathrm{m} \mu$ charge-transfer band of $\mathrm{I}_{2}$ - TEA in MMA (Figure 7) might be considered to involve the absorption band of the $\mathrm{I}_{3}^{-}$ion.

From these results, the following reaction schemes are suggested for the photolysis of the $\mathrm{I}_{2}$-TEA complex in MMA.

$$
\begin{aligned}
\mathrm{I}_{2}+\mathrm{THA} & \rightleftharpoons\left[\mathrm{Et}_{3} \mathrm{~N}---\mathrm{I}_{2} \leftrightarrow \mathrm{Et}_{3} \mathrm{~N}^{\oplus}{ }_{---} \Theta_{\mathrm{I}-\mathrm{I}]}\right. \\
\mathcal{E}_{?} & \rightleftharpoons\left[\mathrm{Et}_{3} \mathrm{~N} \mathrm{I}_{-} \mathrm{I}\right] \mathrm{I} \ominus \\
{\left[\mathrm{Et}_{3} \mathrm{~N} \mathrm{I}_{-} \mathrm{I}\right]-\mathrm{I} \ominus } & \longrightarrow\left[\mathrm{Et}_{3} \mathrm{~N} \cdot \oplus+\cdot \mathrm{I}_{2} \Theta\right]
\end{aligned}
$$

$$
\begin{aligned}
& \stackrel{\mathrm{Et}_{3} \mathrm{~N}}{\longrightarrow} \mathrm{Et}_{3} \mathrm{~N} \oplus-\mathrm{HI} \ominus+\mathrm{Et}_{2} \mathrm{~N}-\mathrm{CH}-\mathrm{CH}_{3} \\
& \text { (II) (III) } \\
& \mathrm{Et}_{2} \mathrm{~N}-\mathrm{CH}-\mathrm{CH}_{3} \stackrel{h_{\nu}}{\longrightarrow} \mathrm{Et}_{2} \mathrm{~N}-\mathrm{CH}-\mathrm{CH}_{3}+\mathrm{I} \cdot \\
& {\left[\mathrm{Et}_{3} \mathrm{~N}^{\oplus}-\mathrm{I}\right] \mathrm{I}^{\ominus}+\mathrm{I}_{2} \longrightarrow\left[\mathrm{Et}_{3} \mathrm{~N}^{\oplus}-\mathrm{I}\right] \mathrm{I}_{3} \ominus} \\
& \mathrm{Et}_{3} \oplus-\mathrm{HI} \ominus+\mathrm{I}_{2} \longrightarrow \mathrm{Et}_{3} \mathrm{~N}^{\oplus}-\mathrm{HI}_{3} \ominus
\end{aligned}
$$

The iodine radicals produced by eq 3 would recombine with each other to form an iodine molecule, and otherwise abstract a hydrogen atom from TEA or MMA to produce HI.

Bhome and $\mathrm{Krause}^{22}$ reported that from the reaction of trimethylamine with chlorine, chlorotrimethyl ammonium chloride was produced. It is also known that in the case of the ringformation reaction of $N$-haloamine with sulfuric acid, the first step is the salt formation between $N$-haloamine and sulfuric acid, and then the cation is converted into a free radical by either heat or irradiation of ultraviolet light. ${ }^{23}$

$$
\begin{aligned}
& \mathrm{H} \\
& \mathrm{R}-\mathrm{N}-\mathrm{R}+\mathrm{H}_{2} \mathrm{SO}_{4} \longrightarrow \mathbf{R}-\mathbf{N} \oplus-\mathbf{R}+\mathrm{HSO}_{4} \ominus \\
& \text { '́l } \\
& \mathrm{R}-\mathrm{N} \oplus \mathrm{H}-\mathrm{R} \longrightarrow \mathrm{R}-\mathrm{N} \oplus \mathrm{H}-\mathrm{R}+\cdot \mathrm{Cl} \\
& \text { '́l }
\end{aligned}
$$

Recently, Romans, et al., ${ }^{24}$ suggested that iodine and the tetramethylhydrazine(TMH) complex decomposed in various polar solvents as follows

$$
\begin{aligned}
& \mathrm{TMH}+\mathrm{I}_{2} \rightleftharpoons \mathrm{TMH}-\mathrm{I}_{2} \rightleftharpoons\left[\mathrm{TMH}^{\oplus}-\mathrm{I}_{2}\right]^{\Theta_{\mathrm{solv}}} \\
& \longrightarrow[\mathrm{TMH} \cdot \oplus]_{\mathrm{SOlv}}+\left[\mathrm{I}_{2} \cdot \ominus\right]_{\mathrm{solv}} \\
& {\left[\mathrm{I}_{2} \cdot \ominus\right]_{\mathrm{Solv}} \longrightarrow[\mathrm{I} \ominus]_{\mathrm{SOIV}}+\mathrm{I} \cdot}
\end{aligned}
$$

These reaction mechanisms may be applicable to the $\mathrm{I}_{2}$-TEA system, and at any rate it is reasonable to assume that the radical cation (I) must be formed by eq 1 and 2 . $\gamma$-Iodomethyl 
pyridine is believed to have been formed as the intermediate of the reaction of iodine and $\gamma$-pycoline. ${ }^{25}$ The authors ascertained that alkyl iodides were able to initiate the photopolymerization of MMA in the presence of TEA or sodium thiosulfate, though the system of alkyl iodide and the ammonium salt of TEA could not initiate the polymerization of MMA by UV irradiation. ${ }^{26}$ The details will be described in a later report.

These considerations, therefore, suggest that the intermediate radical (I) may produce $N, N$ diethyl- $\alpha$-iodoethylamine (III), the photolysis of which presumably forms the radical (IV) initiating the polymerization of MMA, and that the other reactions of (III) may produce $N, N$-diethylvinylamine, $\alpha$-N,N-diethylaminoethyltriethyl ammonium iodide and so on.

\section{REFERENCES}

1. C. Reid and R. S. Mulliken, J. Amer. Chem. Soc., 76, 3869 (1954).

2. H. Yada, J. Tanaka, and S. Nagakura, Bull. Chem. Soc. Japan, 33, 1660 (1960).

3. H. Tsubomura, J, Amer. Chem. Soc., 82, 40 (1960).

4. H. Tsubomura and R. P. Lang, ibid., 83, 2085 (1961).

5. P. A. D. deMaine, J. Chem. Phys., 26, 1192 (1957).

6. H. A. Benesi and J. H. Hildebrand, J. Amer. Chem. Soc., 71, 2703 (1949).

7. L. J. Andrews and R. M. Keefer, ibid., 74, 458 (1952).

8. S. Nagakura, ibid., 80, 520 (1958).
9. P. Boule, ibid., 90, 517 (1968).

10. H. D. Bist and W. B. Person, J. Phys. Chem., 73, 482 (1969).

11. C. D. Schumulbach and D. M. Hart, J. Amer. Chem. Soc., 86, 2347 (1964).

12. K. Toyoda and W. B. Person, ibid., 88, 1629 (1966).

13. S. Okamura, N. Kanoh, and T. Higashimura, Makromol. Chem., 47, 35 (1961).

14. N. Kanoh, T. Higashimura, and S. Okamura, ibid., 65, 65 (1962).

15. N. Kanoh, A. Gotoh, T. Higashimura, and S. Okamura, ibid., 63, 106 (1963).

16. K. Tsuji, K. Takakura, M. Nishii, K. Hayashi, and S. Okamura, J. Polym. Sci., Part A-1, 4, 2028 (1966).

17. K. Tsuji, Y. Imanishi, K. Hayashi, and S. Okamura, Polym. Letters, 5, 449 (1967).

18. D. Pramanick and S. R. Palit, J. Polym. Sci., Part A-1, 7, 47 (1969).

19. H. L. Cohen and L. M. Minsk, J. Org. Chem., 24, 1404 (1959).

20. G. Lahan and R. Mayer, Z. Chem., 7, 12 (1967).

21. R. E. Buckles, J. P. Yuk, and A. I. Popov, J. Amer. Chem. Soc., 74, 4379 (1952).

22. H. Bhome and W. Krause, Chem. Ber., 84, 170 (1951).

23. S. Wawzonek and P. J. Thelen, J. Amer. Chem. Soc., 72, 2118 (1950).

24. D. Romans, W.H. Bruning, and C. J. Michejda, ibid., 91, 3859 (1969).

25. I. Haque and J. L. Wood, J. Phys. Chem., 72, 2438 (1968).

26. N. Sakota, T. Nagasaki, and S. Sakai, unpublished results.

27. E. S. C. Ginsberg, T. G. Fox, and H. F. Marson, Polymer, 3, 97 (1962). 